\title{
Carbon at the coastal interface
}

The extent to which coastal-ocean regions act as a sink for carbon dioxide has been enigmatic. An estimate based on more than 3 million observations suggests a smaller sink than was thought, concentrated at high latitudes.

\section{NICOLAS GRUBER}

$\mathrm{T}$ The thin strip of coastal ocean at the interface between land and the vast areas of the open sea contains some of the most biologically productive areas of the world's oceans. These coastal regions support most of the marine resources harvested by humans ${ }^{1}$, despite covering only a tiny fraction of the ocean's surface area. One would expect these regions to act as strong sinks for atmospheric carbon dioxide because of their high rates of photosynthetic carbon fixation. Indeed, an early estimate ${ }^{2}$ from the late 1990 s suggested a coastal-ocean sink strength of about 1 petagram of carbon per year $\left(\mathrm{PgCyr}^{-1} ; 1\right.$ petagram is $10^{15} \mathrm{~g}$ ) - a value that, when combined with the open-ocean sink strength ${ }^{3}$ of about $2.3 \pm 0.7 \mathrm{PgC}^{-1}{ }^{-1}$, would make the ocean by far the largest sink for the $\mathrm{CO}_{2}$ that humans emit every year into the atmosphere ${ }^{3}$. Reporting in Global Biogeochemical Cycles, Laruelle and coauthors ${ }^{4}$ now show that the global coastal ocean is a much smaller $\mathrm{CO}_{2}$ sink than was thought, amounting to only about $0.2 \mathrm{PgCyr}^{-1}$.

The authors' result continues a trend toward progressively smaller estimates, with the most recent previous publication ${ }^{5}$ suggesting a value between 0.2 and $0.5 \mathrm{PgC} \mathrm{yr}^{-1}$. But previous global estimates were based on the extrapolation of a small number of observations (often not more than a few hundred), whereas Laruelle et al. constrained estimates of the coastal air-sea $\mathrm{CO}_{2}$ fluxes nearly globally using more than 3 million observations of the surface-ocean concentration of $\mathrm{CO}_{2}$ from a recently compiled database ${ }^{6}$.

The authors divided the global coastal ocean into 45 segments and then determined the air-sea $\mathrm{CO}_{2}$ flux for each segment using an approach that depended on the data density. In well-sampled regions, each segment was sub-divided into a grid, data were 'binned' into the grid's cells, and flux was computed directly on the basis of the gridded data. In areas that were sampled less well, the data were grouped according to water depth and other parameters. If the coverage was extremely limited, the researchers simply averaged the few available observations. Through this adaptive extrapolation method, they were able to constrain the air-sea $\mathrm{CO}_{2}$ fluxes for $96 \%$ of the global coastal

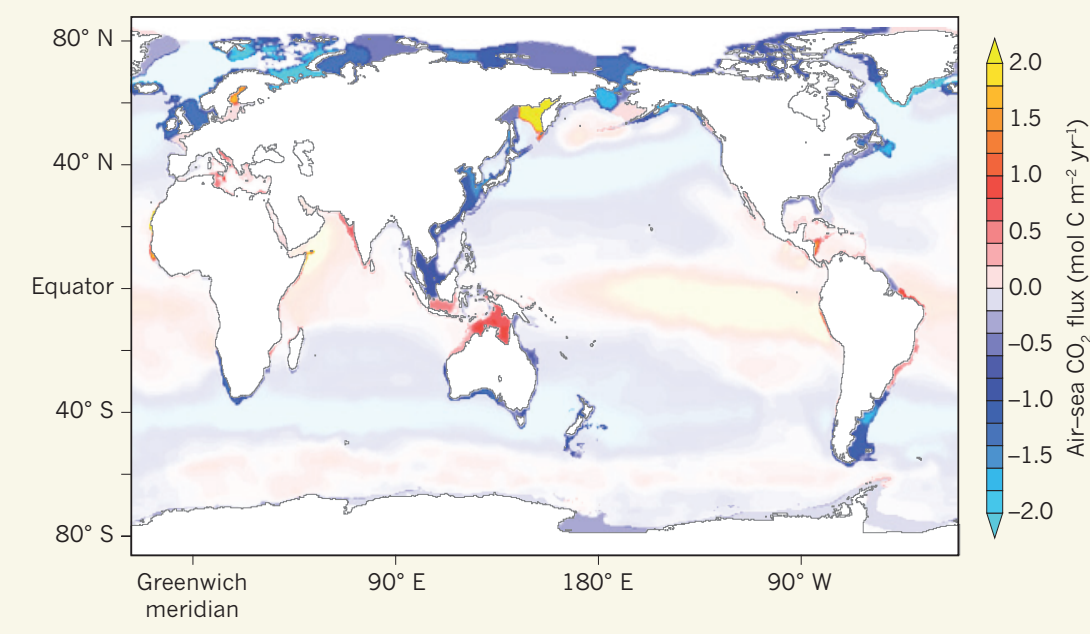

Figure 1 | Global map of air-sea $\mathrm{CO}_{2}$ fluxes. Laruelle et al. ${ }^{4}$ report the average flux density of coastal ocean regions (strong colours) based on more than 3 million observations. Data for the open ocean ${ }^{12}$ are shown in fainter colours, for comparison. Blue colours represent carbon sinks, other colours represent carbon sources. Units of flux are moles of carbon per square metre per year.

ocean. This great leap forward in data coverage and methodology compared with all previous studies makes this estimate by far the most solid and reliable, thus providing an important constraint for the global carbon cycle.

A striking observation arising from the coastal air-sea $\mathrm{CO}_{2}$ fluxes is that not all regions are sinks - many are sources of $\mathrm{CO}_{2}$ to the atmosphere (Fig. 1). The flux distribution follows largely a latitudinal trend, with coastal regions at low latitudes generally losing $\mathrm{CO}_{2}$ to the atmosphere, whereas those at higher latitudes, and especially in the Arctic, take it up. To a zero-order approximation, this follows the distribution of $\mathrm{CO}_{2}$ fluxes in the open ocean, where the main sources to the atmosphere are also found at low latitudes, and the largest sinks at mid- to high latitudes ${ }^{7}$.

At first thought, it is surprising that the distribution of $\mathrm{CO}_{2}$ sources and sinks does not follow that of primary production - for example, there are modest differences in $\mathrm{CO}_{2}$ flux between the coastal ocean and the adjacent open ocean, even though the magnitude of biological productivity in these two systems differs by more than fivefold. The explanation of this puzzling finding is that many processes ultimately determine whether a region is a source or sink of atmospheric $\mathrm{CO}_{2}$ (ref. 8). In general, the outcome depends on a complex interaction between the extent of warming or cooling (which alters the solubility of $\mathrm{CO}_{2}$ ), the amount of biological activity that removes $\mathrm{CO}_{2}$ from the system, and how much $\mathrm{CO}_{2}$ is supplied by upwelling and mixing from deeper waters. In coastal systems, additional complexity arises from the supply of inorganic and organic carbon from rivers on the adjacent land. The general latitudinal trend observed by Laruelle and co-workers suggests that warming and cooling dominate the distribution of the air-sea $\mathrm{CO}_{2}$ fluxes, but the many deviations from this trend remind us how crucial other processes are in modifying the coastal carbon cycle.

Despite the vast increase in the amount of data considered in the new study compared with previous reports, the spatial, and especially the temporal, coverage of the data are still quite poor. The full seasonal cycle is resolved in only a handful of regions, and spatial coverage is nearly always too coarse to properly take into account the high spatio-temporal variability that characterizes coastal systems. The uncertainty associated with the time-mean estimate provided by Laruelle $e t$ al. therefore remains rather large. 
The data are also insufficient to assess whether there are any trends in coastal fluxes, which is a serious gap when considering that the influence of human activity on coastal systems is increasing rapidly ${ }^{9}$. Of particular interest is how changes in the lateral supply of carbon from land will alter the sink-source balance of coastal systems ${ }^{10}$, and how other perturbations, such as ocean acidification, deoxygenation and increasing nutrient load, will manifest themselves in the coastal carbon cycle and ultimately alter the coastal ocean's ability to take up atmospheric $\mathrm{CO}_{2}$.

Finally, a global uptake flux of $0.2 \mathrm{PgC}^{-1}$ by the coastal ocean may seem modest, but it represents an invaluable ecosystem service.
Using the current $\mathrm{CO}_{2}$ price of about $€ 5$ (US\$6) per tonne of $\mathrm{CO}_{2}$ in the European Union emissions-trading system ${ }^{11}$, this service may be worth about $€ 1$ billion per year.

Nicolas Gruber is in the Environmental Physics Group, Institute of Biogeochemistry and Pollutant Dynamics, ETH Zurich, 8092 Zurich, Switzerland.

e-mail:nicolas.gruber@env.ethz.ch

1. Pauly, D. \& Christensen, V. Nature $\mathbf{3 7 4}, \mathbf{2 5 5}-257$ (1995).

2. Tsunogai, S., Watanabe, S. \& Sato, T. Tellus B. 51, 701-712 (1999)

3. Ciais, P. et al. in Climate Change 2013: The Physical Science Basis. Contribution of Working Group I to the Fifth Assessment Report of the Intergovernmental
Panel on Climate Change (Stocker, T. F. et al.) Ch. 6, 465-570 (Cambridge Univ. Press, 2013).

4. Laruelle, G. G., Lauerwald, R., Pfeil, B. \& Regnier, P. Glob. Biogeochem. Cycles http://dx.doi. org/10.1002/2014GB004832 (2014)

5. Bauer, J. E. et al. Nature 504, 61-70 (2013).

6. Bakker, D. C. E. et al. Earth Syst. Sci. Data 6, 69-90 (2014).

7. Gruber, N. et al. Glob. Biogeochem. Cycles $\mathbf{2 3}$ GB1005 (2009)

8. Takahashi, T. et al. Deep Sea Res. Part II Top. Stud. Oceanogr. 56, 554-577 (2009).

9. Doney, S. C. Science 328, 1512-1516 (2010).

10. Regnier, P. et al. Nature Geosci. 6, 597-607 (2013).

11.Koch, N. et al. Energy Policy 73, 676-685 (2014).

12.Landschützer, P. et al. Glob. Biogeochem. Cycles 28, 927-949 (2014).

This article was published online on 10 December 2014. 